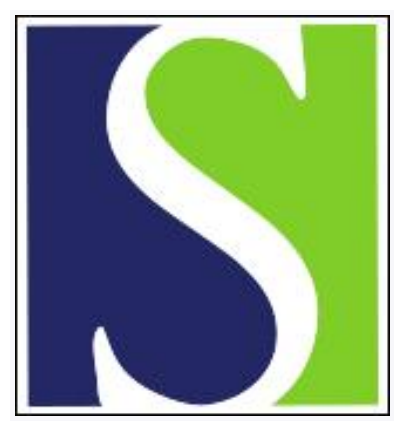

Scand J Work Environ Health 1993;19(4):217-226

https://doi.org/10.5271/sjweh.1480

Issue date: 01 Aug 1993

Observations on the dose-response curve for arsenic exposure and lung cancer.

by Hertz-Picciotto I, Smith AH

Affiliation: Department of Epidemiology, University of North Carolina, Chapel Hill 27599-7400.

This article in PubMed: www.ncbi.nlm.nih.gov/pubmed/8235510

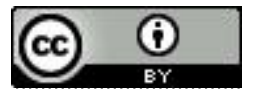




\title{
Observations on the dose-response curve for arsenic exposure and lung cancer
}

\author{
by Irva Hertz-Picciotto, PhD, ${ }^{1}$ Allan $\mathrm{H}$ Smith, $\mathrm{MD}^{2}$
}

\begin{abstract}
HERTZ-PICCIOTTO I, SMITH AH. Observations on the dose-response curve for arsenic exposure and lung cancer. Scand J Work Environ Health 1993;19:217-26. Occupational studies in three countries have related quantitative estimates of arsenic exposure to lung cancer risks. Mine exposures in China appear to incur a higher relative risk than arsenic exposures elsewhere. All of the studies with quantitative data are consistent with a supralinear dose-response relationship. Two studies are also consistent with a linear relationship over an elevated background risk of lung cancer among arsenic-exposed workers. Neither toxicokinetic mechanisms nor confounding from age, smoking, or other workplace carcinogens that differ by exposure level appear likely to explain this curvilinearity. Plausible explanations include (i) synergism (with smoking) which varies in magnitude according to the level of arsenic exposure, (ii) long-term survivorship in higher exposure jobs among the healthier, less susceptible individuals, (iii) exposure estimate errors that were more prominent at higher exposure levels as a result of past industrial hygiene sampling or worker protection practices.
\end{abstract}

Key terms: epidemiologic methods, exposure assessment, healthy worker survivor effect, nonlinearity, occupational cancer, occupational exposures, supralinearity.

A large body of literature consistently links arsenic inhalation exposure to the risk of lung cancer in humans $(1-3)$. Data relating quantified estimates of arsenic exposure to lung cancer mortality have been reported for workers representing six occupational cohorts $(4-10)$. In a brief report (11), we noted that data from three smelter studies $(4-6)$ were consistent with a curvilinear dose-response in which slopes were steeper at low than at high cumulative exposures, and we discussed the implications of this supralinearity for risk extrapolations.

In this paper, we evaluate all published reports which relate lung cancer risk to quantified occupational arsenic exposure. In particular, the goals of this paper are to synthesize the findings; reconcile discrepancies among studies, where possible; generate "testable" scientific hypotheses regarding the magnitude and shape of the dose-response curves; assess the strength of evidence for each of these hypotheses; and provide guidance for future research on this issue.

The presence of a monotonic dose-response relation between exposure and outcome is one of several criteria used in assessing the strength of evidence for causal inference (12). In addition, dose-response data from epidemiologic studies increasingly play a

1 Department of Epidemiology, University of North Carolina, Chapel Hill, North Carolina, United States.

2 Department of Biomedical and Environmental Health Sciences, University of California, Berkeley, California, United States.

Reprint requests to: Dr I Hertz-Picciotto, Department of Epidemiology, University of North Carolina, Chapel Hill, North Carolina 27599-7400, USA. role in standard setting and risk assessment for both occupational and environmental exposures (13). To extrapolate from high to low exposure scenarios, linear models are frequently used. That the data for arsenic-exposed workers suggest nonlinear relations underscores the need to understand what factors serve to influence or distort dose-response curves in order that the most scientifically sound risk estimates be obtained.

To begin, we (i) provide background information on these studies and present the dose-response data in graphic form; we then (ii) discuss variation in the magnitude of the risks, (iii) evaluate the shape of the dose-response curves, and (iv) explore possible explanations for the curvature observed in several of the studies.

\section{Background and dose-response relationships}

Studies providing dose-response data for occupational arsenic exposure and lung cancer risk have been conducted on large cohorts of smelter workers in Tacoma, Washington (4), Anaconda, Montana (5), and Ronnskar, Sweden $(6,7)$; workers at six smaller smelters in the United States, one at Garfield, Utah, and five at other sites (10); a cohort of insecticide manufacturing workers in Midland, Michigan (8); and a cohort of mainly miners but also some smelter workers employed by a tin corporation at numerous sites in China (9). Table 1 summarizes these studies, including their design, location, industry, number of lung cancer cases, type of analysis, variables controlled for, and choice of referents. Except for the study of miners in China (9), all of the studies ex- 
Table 1. Six occupational studies with quantified dose-response data on lung cancer and arsenic exposure. (SMR $=$ standardized mortality ratio, $\mathrm{PMR}=$ proportionate mortality ratio, $\mathrm{DSDR}=$ directly standardized death rate, $\mathrm{OR}=$ odds ratio, $\mathrm{RR}=$ risk ratio)

\begin{tabular}{|c|c|c|c|c|c|c|}
\hline Reference & Industry & Location & Design & Measure of effect & Unexposed referents & $\begin{array}{l}\text { Number of } \\
\text { lung cancer } \\
\text { cases }^{a}\end{array}$ \\
\hline $\begin{array}{l}\text { Enterline et al } \\
1987(4)\end{array}$ & Smelting & $\begin{array}{l}\text { Tacoma, } \\
\text { Washington }\end{array}$ & Cohort & $S M R^{b}$ & $\begin{array}{l}\text { White male population, } \\
\text { Washington State }\end{array}$ & 104 \\
\hline $\begin{array}{l}\text { Lee-Feldstein } \\
1986(5)\end{array}$ & Smelting & $\begin{array}{l}\text { Anaconda, } \\
\text { Montana }\end{array}$ & Cohort & $S_{M} R^{b}$ and DSDR & $\begin{array}{l}\text { White male population } \\
\text { of Idaho, Montana and } \\
\text { Wyoming, combined }\end{array}$ & 259 \\
\hline Jarup et al 1989 (6) & Smelting & Ronnskar, Sweden & Cohort & $S M R^{b}$ & $\begin{array}{l}\text { Male population of } \\
\text { county in Sweden }\end{array}$ & 106 \\
\hline $\begin{array}{l}\text { Jarup \& Pershagen } \\
1991(7)\end{array}$ & Smelting & Ronnskar, Sweden & $\begin{array}{l}\text { Nested } \\
\text { case-referent }\end{array}$ & $\begin{array}{l}\text { OR adjusted for } \\
\text { age and smoking }\end{array}$ & $\begin{array}{l}\text { Workers exposed to }<250 \\
\text { cumulative } \mu \mathrm{g} \cdot \mathrm{m}^{-3} \text {-years }\end{array}$ & 107 \\
\hline Taylor et al 1989 (9) & $\begin{array}{l}\text { Mining mostly, } \\
\text { some smelting }\end{array}$ & $\begin{array}{l}\text { Yunnan Province, } \\
\text { China }\end{array}$ & $\begin{array}{l}\text { Nested } \\
\text { case-referent }\end{array}$ & $\begin{array}{l}\text { OR adjusted for } \\
\text { age, radon, year of } \\
\text { hire and smoking }\end{array}$ & $\begin{array}{l}\text { Lowest quartile of } \\
\text { exposure among cases } \\
\text { and referents combined }\end{array}$ & 107 \\
\hline Ott et al $1974(8)$ & $\begin{array}{l}\text { Insecticide } \\
\text { manufacturing }\end{array}$ & Midland, Michigan & Case-referent & $\mathrm{PMR}^{\mathrm{b}, \mathrm{d}}$ & $\begin{array}{l}\text { Workers exposed to }<40 \\
\text { cumulative } \mu \mathrm{g} \cdot \mathrm{m}^{-3} \text {-years }\end{array}$ & 132 \\
\hline $\begin{array}{l}\text { Enterline et al } \\
1987 \text { (10) }\end{array}$ & $\begin{array}{l}\text { Smelting and } \\
\text { mining }\end{array}$ & $\begin{array}{l}\text { Six sites in United } \\
\text { States, largest was } \\
\text { in Utah }\end{array}$ & Cohort & $\begin{array}{l}\mathrm{RR}^{\mathrm{b}} \text { (=observed/ } \\
\text { expected, for } \\
\text { which expected } \\
\text { deaths were } \\
\text { based on total } \\
\text { cohort) }\end{array}$ & $\begin{array}{l}\text { Workers exposed to }<100 \\
\text { cumulative } \mu \mathrm{g} \cdot \mathrm{m}^{-3} \text {-years }\end{array}$ & 70 \\
\hline
\end{tabular}

a Cases were defined as deaths from lung cancer for all studies except that of Taylor et al (9), who defined cases as members of the cohort who were diagnosed with lung cancer and were living in 1985.

Standardized for age and calendar year.

a Nested within the cohort of Jarup et al (6).

Workers exposed to asbestos were excluded.

amined mortality. Within the two nonsmelter cohorts, a nested case-referent design was applied: one using living lung cancer cases and living referents (9) and the other using deaths from lung cancer as cases and deaths from other causes as referents (8). Both a cohort (6) and a nested case-referent (7) study analyzed quantified exposure data for employees at the Ronnskar smelter. The study of six small smelters also used internal comparisons. The number of observed deaths was compared with the number expected on the basis of the experience of all white smelter workers in the cohort (10). Although other reports have also appeared for some of these cohorts, they included shorter follow-up $(14,15)$, lacked quantified air measurements $(15-19)$, or used an incorrect method of analysis $(20,21)$.

In figure 1, lung cancer risk is plotted against arsenic exposures for the three large cohorts of smelter workers which were compared with external referents. Arsenic exposure, when originally reported as cumulative micrograms per cubic meter-years or milligrams per cubic meter-months, was converted into units of cumulative milligrams per cubic meter-years. In these studies, risk ratios for lung cancer were estimated by the standardized mortality ratio (SMR), for which expected deaths were derived from the application of death rates from a general population in the same state or region to the age, calendar year, and gender distribution in the cohort of interest. Note that the axes in figure 1 differ in the ranges for both the independent and dependent variables due to dif- ferences among the studies in the range of estimated exposures and in the range of observed SMR values. At the Anaconda smelter, workers were divided into cohorts by date of first employment. The cohort hired prior to 1925 and the one hired in 1925-1947 are shown.

Figure 2 presents similar plots, with arsenic exposure in the same units, for two nested case-referent studies $(8,9)$ and for the cohort study which relied on internal comparisons (10). In these studies, the risk ratios for lung cancer were estimated with the use of different measures. The report on miners in China provided multivariate odds ratios comparing the upper three quartiles of exposure to the bottom quartile (9); the report on insecticide manufacturing workers calculated proportionate mortality ratios for lung cancer standardized to a cohort of unexposed decedents in the same industry (8); the study of six small-to-moderate sized smelters reported SMR values for which the expected numbers of deaths were based on the overall cohort, adjusted for age, calendar year, and latency (10). Thus the analysis for this group of smelters involved only internal comparisons among exposure levels. For this last-mentioned study, we divided all of the risk ratios by the risk ratio in the lowest exposure group so that a value of 1.0 on the $y$-axis corresponded to the risk for those with $<100 \mu \mathrm{g} \cdot \mathrm{m}^{-3}$-years of exposure. This procedure transforms the effect measures to estimated risk ratios that are more comparable to those presented in the other studies. 

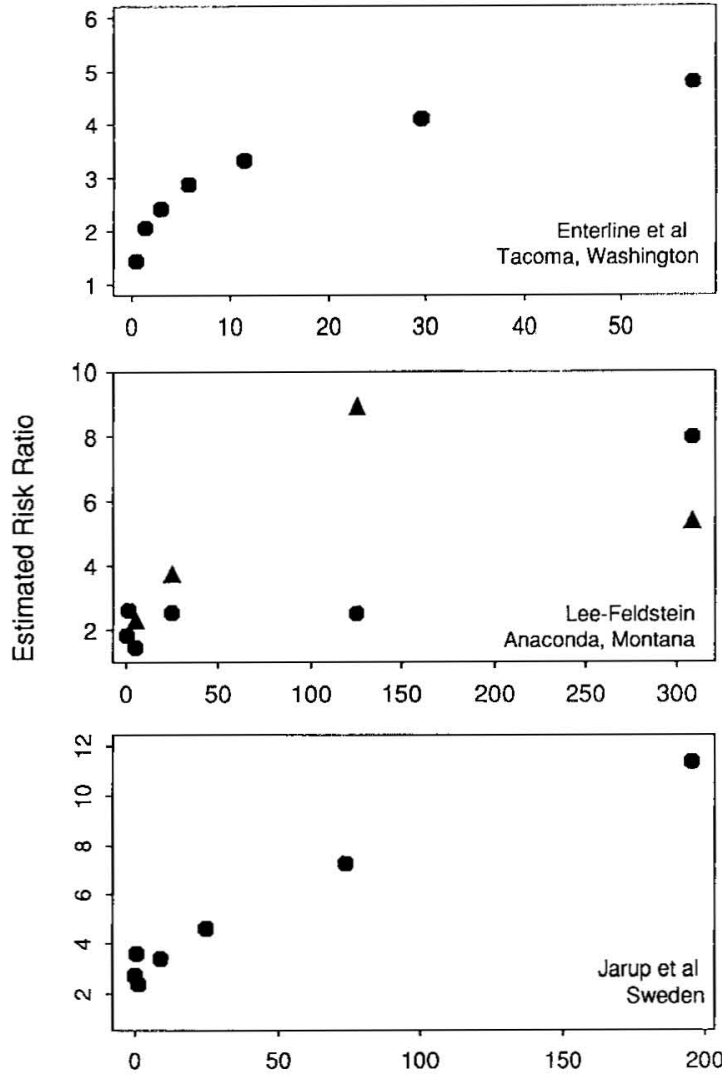

Cumulative Arsenic Exposure: (mg/cubic meter)-years

Figure 1. Dose-response for lung cancer in three occupational cohorts exposed to arsenic. The estimated risk ratios were based on external comparison groups and plotted against cumulative arsenic exposure measured in milligrams per cubic meter-years. Because the range of cumulative exposure varied considerably across studies, the $x$-axes are on different scales for the three cohorts. In reference 5 (LeeFeldstein), the study population was divided into cohorts based on the year of hire. (Triangles $=$ those hired before 1925, circles $=$ those hired in 1925-1947, Enterline et $\mathrm{al}=$ reference 4 , Lee-Feldstein $=$ reference 5 , Jarup et $\mathrm{al}=$ reference 6)

\section{Variation in the magnitude of risk}

The data from the miners' study (9) and the study of insecticide manufacturing workers (8) appear to show a greater potency of arsenic (ie, a greater increase in risk for a given level of cumulative exposure) than the three large smelter studies. For instance, doses in the range of 4-15 cumulative $\mathrm{mg} \cdot \mathrm{m}^{-3}$-years induced a two- to fourfold increase in each of the three smelter studies (4-6), while similar exposures were associated with more than a $20-$ fold increase in lung cancer risk among the miners in China (9) and a four- to sevenfold increase among insecticide manufacturing workers (8).

Part of this discrepancy may be due to an underestimation of exposures, at least in the mines. Table 2 summarizes data reported in the six studies on es-

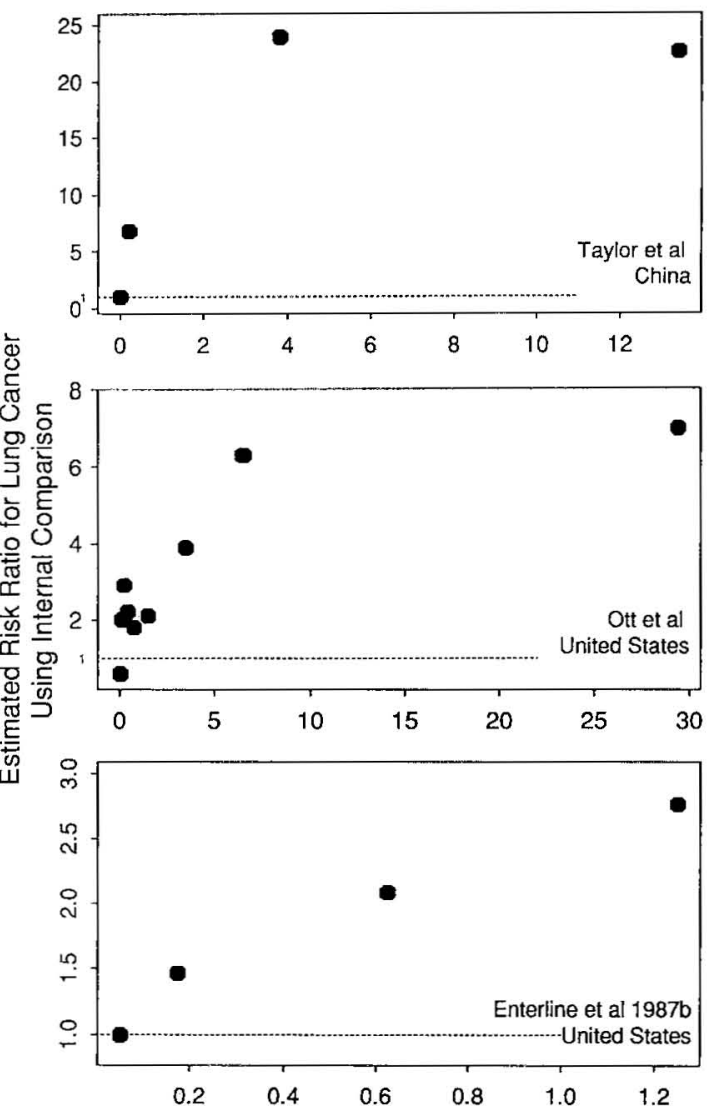

Cumulative Arsenic Exposure: (mg/cubic meter)-years

Figure 2. Dose-response for lung cancer in three occupational studies of arsenic exposure. The estimated risk ratios were based on internal comparisons and plotted against cumulative arsenic exposure measured in milligrams per cubic meter-years. Because the range of cumulative exposure varied considerably across studies, the $x$-axes are on different scales for the three studies. (Taylor et al $=$ reference 9 , Ott et al $=$ reference 8 , Enterline et al $=$ reference 10 )

timated arsenic exposure based on historical measurements. Ranges are shown where department-specific data were used. The arsenic measurements in the mines in China (9) appear to be substantially lower than those in the three large smelters. For instance, after 1951 they are orders of magnitude lower than the high exposures for similar periods in the smelter studies and appear to be similar to concentrations reported for the six smaller smelters. These dramatic differences suggest that the exposure estimates for the mines in China may have been too low. In the insecticide manufacturing plant (8), concentrations were similar to those in the large smelters; the authors in fact asserted that the exposures may have been overestimated.

Statistical biases were probably not sufficient to explain the higher risk ratios in nonsmelting indus- 
Table 2. Comparison of reported exposure levels.

\begin{tabular}{|c|c|c|c|c|}
\hline \multirow{2}{*}{ Reference } & \multirow{2}{*}{ Period } & \multicolumn{3}{|c|}{ Arsenic in worksite air $\left(\mathrm{mg} \cdot \mathrm{m}^{-3}\right)$} \\
\hline & & Low & Medium & High \\
\hline Enterline et al, 1987 (4) & $\begin{array}{l}1940-1957 \\
1958-1976\end{array}$ & $\begin{array}{l}0.04-0.5 \\
0.01-0.3\end{array}$ & $\begin{array}{l}\cdots \\
\cdots\end{array}$ & $\begin{array}{l}0.8-2.9 \\
0.4-1.5\end{array}$ \\
\hline Lee-Feldstein, 1986 (5) & & 0.38 & 7.03 & 61.99 \\
\hline Jarup et al, 1989, and Jarup \& Pershagen, $1991(6,7)$ & $\begin{array}{l}1934-1939 \\
1940-1949 \\
1950-1981\end{array}$ & $\begin{array}{c}0.5-2.5 \\
0.05-1 \\
0-0.05\end{array}$ & $\begin{array}{l}\cdots \\
\cdots \\
\cdots\end{array}$ & $\begin{array}{l}10-50 \\
5 \\
0.2-1.0\end{array}$ \\
\hline Taylor et al, 1990 (9) & $\begin{array}{c}\text { Before } 1952 \\
1952-1959 \\
1960-1969 \\
1970-1979 \\
1980 \text { and later }\end{array}$ & $\begin{array}{l}\cdots \\
\cdots \\
\cdots \\
\cdots\end{array}$ & $\begin{array}{l}0.42 \\
0.06 \\
0.04 \\
0.03 \\
0.01\end{array}$ & $\begin{array}{l}\ldots \\
\cdots \\
\cdots \\
\cdots\end{array}$ \\
\hline Ott et al, 1974 (8) & $\begin{array}{l}1943 \\
1952\end{array}$ & $\begin{array}{l}0.18 \\
0.26\end{array}$ & $\begin{array}{l}\cdots \\
\cdots\end{array}$ & $\begin{array}{l}19.0 \\
40.8\end{array}$ \\
\hline Enterline et al, $1987(10)$ & $1938-1980$ & $0.001-0.01$ & $\cdots$ & $0.01-0.1$ \\
\hline
\end{tabular}

tries. For instance, upward bias from the use of odds ratios (where lung cancer may not have been rare and referents were not incidence-density sampled) or attenuation of SMR values in the cohort studies (as a result of the healthy worker effect when external comparisons were used) would have had a small net impact on the measures of association. Lower background rates, however, may explain the higher risk ratios in the miners' study. A higher relative risk could represent a similar absolute risk from arsenic exposure across studies.

The potency of arsenic exposure in the mines may have appeared inflated by confounding from or interaction with radon, nickel, cadmium, and chromium. All of these carcinogens were present and had been measured in the mines (9). Ninety-three percent of the workers had some radon exposure (22). A smaller contribution to the discrepancy could have resulted from differences in particle size, proportion in the trivalent versus pentavalent forms, or, alternatively, personal work practices. Smelter exposures were mostly trivalent arsenic (23), but data were not reported on particle size or valence speciation in the study from China. Some of the smelter studies reported the use of respirators [at the Tacoma smelter respirators were introduced in the 1940s and tested as "99 percent effective" (16)], but protective devices were not mentioned for the miners in China. Similar issues can be raised with respect to the insecticide manufacturing study, in which workers were exposed primarily to lead arsenate and calcium arsenate (8).

Taylor et al (9) could not successfully separate the effects of mining from smelting exposures because too few study subjects were employed solely in the smelter. Other studies conducted in Sweden (24) and Utah (25) have not demonstrated higher risks from arsenic exposures in mining as compared with smelting. These studies do not, however, preclude differences, for example, in silica content, when ores mined in China are compared with those from elsewhere.

The large difference in apparent potency between the Chinese mine exposures and exposures in smelters and mines elsewhere remains enigmatic. Underestimation of exposure, interactions with other carcinogenic exposures (eg, radon, nickel, etc), and a higher proportion of susceptible individuals are the most likely factors to have contributed to the apparent discrepancy. The apparently higher potency at one insecticide manufacturing plant may also have been a result of an underestimation of exposure or interactions with other carcinogenic substances in the workplace.

\section{Shape of the dose-response curve}

The data from several of the studies shown in the figures suggest a possibly nonlinear relationship between occupational arsenic exposures and the risk of lung cancer. Enterline et al (4) found that the data for the Tacoma smelter were best fit by a power function in which the SMR rises at roughly one-third the power of the cumulative dose. To examine whether the data from the other two large smelter studies $(5$, 6) were consistent with a curvature of this type, we did the following analyses: (i) power models were fit to the three smelter cohorts and compared with similar linear models, and (ii) P-value functions (26) were constructed around the SMR at each exposure level in the Ronnskar and Anaconda smelter cohorts and compared with the predicted response based on the model fit to the Washington smelter.

The power and linear models, respectively, took the forms:

$$
E\left[\mathrm{Obs}_{i}\right]=\left(1+b \cdot d_{i}^{a}\right) \cdot \operatorname{Exp}_{i}
$$

and

$$
E\left[\mathrm{Obs}_{i}\right]=\left(1+b \cdot d_{i}\right) \cdot \operatorname{Exp}_{i},
$$


where $E[]$ indicates the expectation of a random variable (in this case from a Poisson distribution), Obs represents the observed deaths at exposure level $i$, $\operatorname{Exp}_{i}$ represents the expected deaths in the absence of exposure, at exposure level $i, b$ is the slope parameter, and $a$ is the power parameter. These models constrain the intercept. Models were also fit with an intercept parameter. Parameters were estimated by iteratively reweighted least squares regression, predicted deaths serving as weights. The best fitting power curve using all points from the three cohorts combined was a poor fit. The major contribution to the lack of fit was two points in the Anaconda smelter data. Linear models provided an even worse fit. When each data set was analyzed separately, better fitting models were obtained, and, in all cases, the power relations provided as good a fit as or a better fit than linear relations. The improvement ranged from minor to substantial.

The comparisons of $\mathrm{P}$-value functions with predictions from the model for the Tacoma smelter gave similar results. With the exception of one point (at $125 \mathrm{mg} \cdot \mathrm{m}^{-3}$ in the Anaconda cohort hired 1925 1947), the curve fell in the central portion of these functions, suggesting general consistency with the fitted curvature of decreasing slope (4). On the other hand, from visual inspection and from the models with unconstrained intercepts, one sees that the data from these two smelter studies $(5,6)$ are also consistent with a linear relationship in which the intercept is above the background level. Finally, a casereferent study nested within the Swedish smelter cohort (6) showed little evidence for a supralinear curvature (7). In yet another study of smelter workers a decreasing slope in the dose-response relationship was noted (10), though the range of exposures was extremely low relative to the ranges in the other occupational cohorts, and the curvature was slight. In fact, this study suggests that the dose-response relationship is much closer to linear at low than at high cumulative exposures. Thus, with one exception, the suggestion of a declining slope for the risk of lung cancer at higher cumulative exposures of arsenic is observed for all of the occupational studies with quantified dose-response data.

By plotting the relative risks rather than their logarithms, we have evaluated dose-response on an additive, rather than on a multiplicative scale. On a multiplicative scale (ie, assuming that a given dose will multiply the risk by the same factor anywhere in the exposure range), the departure from linearity in these data becomes more dramatic. Even those studies which, on an additive scale, appear to be compatible with a linear relationship and an elevated intercept show a clear curvilinear relationship with a decreasing slope on a multiplicative scale.

The dose-response curves for lung cancer risk among arsenic-exposed workers in several studies appear to increase more steeply at lower than at higher exposures. For two smelters $(5,6)$, the data may be consistent with a linear dose-response, but do not contradict such a curvature, and for one of these (6) adjustment for age in a nested case-referent study appears to eliminate any curvature of decreasing slope (7). One must ask "what mechanisms might account for the nonlinearity in the remaining studies?"

\section{Explanations for the nonlinearity}

In this section we postulate several possibilities for the nonlinearity and review the evidence and plausibility of each. Table 3 summarizes our findings, as discussed below.

\section{Artifact of statistical method; confounding by age}

Strictly speaking, SMR values are not comparable if the following two conditions are met: different exposure groups have different age distributions and age-specific mortality ratios with respect to the reference population are heterogeneous. Groups defined by cumulative exposure level are likely to have different age distributions for two reasons. First, those who are older will have had a longer opportunity for employment and hence for accumulating exposure. Since exposure groups refer to person-years rather than persons, a more precise way to say this is that person-years at older ages tend to dominate in the higher exposure groups. Secondly, in many industrial settings, exposures have been reduced over time so that even with the same duration of employment, older workers (more precisely, person-years at older ages) will be overrepresented in the higher exposure categories. Of course, noncomparable age distributions can be addressed through direct standardization, the reporting of age- and dose-specific mortality ratios, multivariate regression (eg, Poisson or logistic) control for age, or a nested case-referent study matching on age.

These numerous alternative analytic strategies were used in different studies, for example, "directly standardized death rates" (5), Poisson modeling (27), and nested case-referent studies that adjusted for age and calendar year $(8,9,10)$. Such analyses did not alter the shapes of the observed dose-response curves, with one exception. Jarup \& Pershagen (7) compared dose-specific odds ratios adjusted for age to the dose-specific SMR values from the original cohort study (6) after standardizing the SMR values to the lowest exposure level and found that the curvature seen in the SMR analysis was absent in the case-referent study after age adjustment.

In case-referent studies, the use of internal comparisons precludes the possibility that the apparent curvature is actually due to fluctuations around a linear relationship with an elevated intercept. That is, the intercept does not represent a background level of risk, since the value of 1.0 was based on a lowexposure group. Furthermore, all of the case-referent studies of arsenic-exposed workers adjusted for 
Table 3. Strength of evidence regarding epidemiologic explanations for the curved dose-response relating arsenic exposure to lung cancer risk. $(++=$ strong support, $+=$ support, $(+)=$ weak support, $\cdots=$ no evidence, $(-)=$ weak evidence against, - = evidence against, ref $=$ reference)

\section{Presence of curvature \\ Explanation \\ Artifact of statistical method, confounding by age \\ Confounding (differential by dose) \\ Other workplace carcinogens}

Smoking

Synergism

Healthy worker survivorship

Exposure misclassification

\begin{tabular}{|c|c|c|c|c|c|}
\hline \multicolumn{6}{|c|}{ Study population ${ }^{a}$} \\
\hline $\begin{array}{c}\text { Tacoma } \\
\text { Washington } \\
\text { smelter }\end{array}$ & $\begin{array}{c}\text { Anaconda } \\
\text { Montana } \\
\text { smelter }\end{array}$ & $\begin{array}{l}\text { Ronnskar } \\
\text { Sweden } \\
\text { smelter }\end{array}$ & $\begin{array}{c}\text { Pesticide } \\
\text { Manufacturing } \\
\text { plant }\end{array}$ & $\begin{array}{l}\text { China } \\
\text { tin mines }\end{array}$ & $\begin{array}{l}\text { Six small } \\
\text { smelters }\end{array}$ \\
\hline$\underset{(\text { ref } 4)}{++}$ & $\begin{array}{c}(+) \\
\text { (ref } 5)\end{array}$ & $\underset{(\text { ref } 6)}{(+)}$ & $\stackrel{+}{+}$ & $\stackrel{+}{++}$ & $\begin{array}{c}(+) \\
(\text { ref } 10)\end{array}$ \\
\hline (ref 4) & $(\overline{r e f} 5)$ & $\stackrel{+}{(\text { ref }} 7$ ) & (ref 8 ) & (ref 9 ) & $\underset{(\text { ref } 10)}{(-)}$ \\
\hline . & (ref 15$)$ & . & . & (ref 22$)$ & $\left(\begin{array}{r}- \\
\text { ref } 10)\end{array}\right.$ \\
\hline . & (ref 21 ) & $\stackrel{+}{(r e f} 7)$ & $\cdots$ & (ref $\overline{9})$ & $\cdots$ \\
\hline . & .. & $\stackrel{+}{+} \underset{(\text { ref } 24)}{ }$ & $\cdots$ & $\cdots$ & $\stackrel{+}{\stackrel{+}{(r e f} 25)}$ \\
\hline$\stackrel{+}{\stackrel{+}{(\text { ref }} 27)}$ & $\stackrel{+}{+}$ & $\underset{(\text { ref } 6)}{(+)}$ & $\cdots$ & $\cdots$ & . \\
\hline$\stackrel{+}{(r e f} 4)$ & $\cdots$ & $\cdots$ & $\cdots$ & $\cdots$ & $\cdots$ \\
\hline
\end{tabular}

a Each column represents a given occupationally-exposed cohort. For some cohorts, different publications assessed different aspects of the arsenic-lung cancer association. Reference numbers in the table designate the publication that addressed the issue for that row, as described in the left column.

age and calendar year through multivariate modeling or standardization in the estimation of the risk ratios. Thus comparisons of the odds ratios among different exposure levels are valid. Two of these studies $(8,9)$ showed unequivocal supralinearity.

Most of the studies did not address the second criterion for noncomparability of dose-specific measures of association, that is, homogeneity across age groups $(7,8,9)$. In one cohort in which the age-arsenic interaction was examined (the Tacoma cohort), the evidence did not support heterogeneity (27). Overall, a variety of analyses indicated that any curvature in the dose-response relationship in five of the six study populations $(4,5,8,9,10)$ was not a result of heterogeneous age distributions among different exposure levels (table 3 ).

\section{Confounding by other carcinogens}

Confounding from other workplace exposures could raise the background rates and may be consistent with some of the studies. However, the higher slopes at lower exposures would suggest that these other exposures decline with increasing arsenic exposure. Generally, exposure to other carcinogens tends to be positively associated with arsenic $(9,10,15)$ and therefore implies a slope that would increase rather than decrease with higher exposure. In one study (9), multivariate analysis was used to control for radon (which was noted by the authors to be highly correlated with arsenic exposure); the curvature shown in figure 2 is after such adjustment. A situation in which other carcinogenic exposures might be inversely related to arsenic exposure is when short-term workers find employment elsewhere in industries with carcinogenic exposures. Unfortunately, occupational studies usually fail to ascertain employment histories after termination at the plant under study.

\section{Confounding by smoking}

The possible contribution of confounding from smoking in the Swedish smelter study is evident from a comparison of the dose-response curves with and without adjustment for smoking (7). This analysis revealed slight confounding as a result of smoking in the medium-exposure groups and "negative confounding" at the highest level of arsenic exposure; that is, with an unadjusted analysis, the odds ratios for arsenic were slightly inflated in the middle range of exposures and markedly depressed at the highest exposure. The percentage of smokers was similar across dose groups in the Anaconda cohort (21) and also among the insecticide manufacturing workers. Thus confounding from smoking which is differential by dose group may at least partially explain the declining slopes in some of the studies (eg, in reference 6) but could not be an explanation in others.

\section{Synergism}

A dose-dependent synergism with smoking that is larger at lower exposures to arsenic than at higher levels would also cause a reduction in slope. This explanation is supported by the findings that lung cancer risks are described by a multiplicative relation between smoking and residential (ie, low) exposure to arsenic (24) but a less than multiplicative (though still synergistic) relation between smoking 
and occupational (ie, high) arsenic exposure (3, 7, $11,24,25)$.

\section{Healthy worker survivor effect}

If employees with greater susceptibility to cancer are also those who leave employment earlier, then the resulting healthy worker survivorship could cause a progressively decreasing slope. Robins (28) found that a model incorporating nonrandom job-leaving (with the less susceptible remaining on the job) fit the Anaconda data better than a model that assumed random job-leaving. Jarup et al (6) noted that a stronger association of risk with intensity rather than duration of exposure could be evidence of healthy survivorship; indeed, in this study, short-term workers had mortality ratios as high or higher than those of long-term workers at the same average intensity, a pattern consistent with possible life-style differences. Arrighi \& Hertz-Picciotto (27) used several methods to control for the healthy worker survivor effect in the Tacoma, Washington, smelter cohort data. Though some methods resulted in a stronger dose-response, none appeared to alter the curvilinear shape substantially.

If other causes of death with shorter latency periods are also related to arsenic in a dose-response manner and occur more frequently among those more likely to develop lung cancer, then competing risks from other causes of death could result in a healthy worker survivor effect and distort an otherwise linear relationship. The first condition has been shown for cardiovascular mortality in the Anaconda cohort (21), but not among the Ronnskar workers (6). Neither study reported on nonmalignant respiratory disease, a cause of death that might show a stronger relationship with cumulative arsenic exposure than cardiovascular-related causes of death. However, the second condition, independence of censoring from the disease of interest, is more difficult to establish. Further examination of competing risks and of a "healthy worker survivor effect" in other cohorts is in order.

\section{Exposure misclassification}

Misclassification of exposure that is more pronounced at higher absolute exposure levels could result in upwardly biased exposure estimates at the higher doses, or downwardly biased exposure estimates at lower levels. Either bias would distort a linear relationship to one that is supralinear. The finding by Enterline et al (4) that urinary measures of arsenic exposure appeared to predict lung cancer risk in a linear fashion suggests that the biological dose may not have been the measured air dose.

Although data on exposure misclassification are difficult to obtain, there are numerous ways in which such biases could occur. Nonrandom selection of locations for collecting industrial hygiene samples could have led to inflated exposure estimates in areas where arsenic levels were highest. In several stud- ies, exposures during certain periods were based on extrapolation from other periods. Rappaport (29) has shown, using empirical industrial hygiene data, that the contribution of variability, both within individuals over time and between individuals within a given job category, leads to significant misclassification.

At worksites where arsenic exposures were heavy, workers may have used respirators; failure to account for such reductions in target tissue doses would produce a spuriously low slope at the high end of the exposure range. Respirators were mentioned in relation to the Anaconda cohort (15) and the Tacoma cohort (16).

Finally, the use of cumulative exposure could be an inappropriate measure if short-term high concentration exposures induce a proportionally greater (or smaller) risk as compared with the same total exposure spread over a longer duration, although peak exposures are generally important only when damage operates via a threshold mechanism $(29,30)$.

The previously described errors in exposure estimates were likely to have varied by the true exposure level: higher exposures would entail greater errors. The magnitude of errors may be proportional to the exposure level. For instance, at levels of $0.1 \mu \mathrm{g} \cdot \mathrm{m}^{-3}$, the error might be two- to fivefold too high or too low, and similarly at $100 \mu \mathrm{g} \cdot \mathrm{m}^{-3}$ the error might again be two- to fivefold, but the magnitude is of course very different. Since larger measurement errors lead to a greater attenuation of relative risk estimates, errors that differ relative to the true exposure would distort a linear relationship to one that had a decreasing slope as exposure increased $(31,32)$.

\section{Toxicologic mechanisms}

Inorganic trivalent arsenic is methylated to the less reactive monomethyl arsinic acid, and again to dimethyl arsinic acid $(21,33-35)$. If methylating enzymes were depleted at high doses, then inorganic arsenic could accumulate and, therefore, lead to a curve with an increasing, not decreasing, slope. Thus, if a metabolic pathway were being saturated, it would have to be a pathway leading to activation, not detoxification. Saturation of bronchial epithelial sites for cellular uptake seems unlikely, given the large surface area of the lung. Increased methylation capacity or other pathways of deactivation that operate only at high doses is another candidate mechanism. The proportion of urinary arsenic excreted in the inorganic (unmethylated) form is about the same over a wide range of exposure levels $(33-38)$, but, since the data do not indicate what proportion of intake is excreted in the urine, the possibility of increased methylation rates at high chronic exposure levels remains. There might be a susceptible subgroup in the population who methylate arsenic less efficiently; this susceptible group might be depleted, with only slight increases in risk for those with a 
more efficient methylating capacity. At this point, evidence for other pathways of deactivation at high exposure levels, or for a bimodal distribution of methylating capacity, is lacking. Both a saturation effect or an increased induction of methylating enzymes is contradicted by existing evidence. In addition, epidemiologic evidence provides no basis for, and in fact contradicts, the hypothesis of a threshold phenomenon (38), a hypothesis that has received attention in the literature (39).

A decrease in "potency" at higher exposures might also occur if increasing particulate matter occurring with arsenic exposure induced more efficient tracheobronchial clearance due to greater mucociliary action and thereby resulted in lower exposures to the target tissue. The induction of such clearance mechanisms is temporary and reversible. Under this scenario, lower doses that do not induce clearance would be more potent; in other words, intensity of exposure would be less of a predictor of carcinogenic potency than duration of exposure. Two studies observed a slightly stronger association of lung cancer risk with intensity rather than with duration of exposure $(4,6)$, but another study found duration to be a much stronger predictor (9). Yet another study revealed no consistent patterns (5).

Arsenic appears to be a co-mutagen. Arsenite has been shown to inhibit DNA repair (40-42), but a nonlinear relationship was noted between sodium arsenite or sodium arsenate and gene amplification activity $(43,44)$. Enterline et al (4) observed a linear relationship between arsenic excreted in urine (inorganic and organic combined) and the SMR. These data suggest a possibility of a linear relationship with the internal dose and air measurements that are deficient as surrogates. Problems in using cumulative air exposure estimates were addressed in the previous subsection.

Several proposed toxicologic mechanisms appear to be refuted by the existing literature, and several others appear not to have been addressed by previous studies. At this point, evidence for a true biological curvilinear dose-response relation between occupational arsenic and lung cancer risk is far weaker than the evidence for several epidemiologic explanations.

\section{Concluding remarks}

Studies in three countries evaluated the risk of lung cancer in relation to quantitative information on occupational arsenic exposure. Mining exposures in China seem to confer a higher risk than smelting exposures in the United States or Sweden, but the reasons are not clear. Synergism with radon or with other metal carcinogens is plausible. An underestimation of exposure in the study of miners in China or a lower background rate of lung cancer may have contributed to this heterogeneity in the estimated carcinogenic potency of arsenic.
Studies with quantified exposure data are compatible with a supralinear (decreasing slope) dose-response relationship. Two of these studies may also be consistent with a linear relationship over a higher background risk of lung cancer among arsenic-exposed workers, but three other studies are clearly not. Yet another study found only a slight curvilinearity, but the exposures were far lower in this study than in the others.

Much of the known metabolic and pharmacokinetic information gathered to date does not explain this curvature. For instance, the induction of methylating enzymes is contradicted by existing data. We have discussed several toxicologic mechanisms that may be operating, such as the induction of other pathways of deactivation at high chronic exposures or the depletion of a subgroup in the population who methylates arsenic less efficiently, but, at present, there appear to be no data addressing these questions. According to the available data, several epidemiologic explanations for the nonlinearity are unlikely. These include confounding by age, by workplace exposures, or by smoking. Prior studies and reanalyses of some existing data are consistent with a role for each of the following: dose-dependent synergism with smoking, dose-related competing risks of death and other contributors to a healthy worker survivor effect, and dose-dependent exposure misclassification involving the overestimation of exposure in the highest exposure job categories. In several of the studies, more than one of these factors could have been distorting the true biological dose-response, and it is also likely that the relative contributions of these explanations differ among studies. Further toxicologic and epidemiologic studies of arsenic and lung cancer should be designed to evaluate these mechanisms.

The significance of the observed curvature in the dose-response curve extends beyond the specific case of arsenic and lung cancer. Several of the proposed mechanisms might apply equally to studies of any occupational carcinogen. For very few agents are there adequate data to allow an evaluation of doseresponse relationships over a wide range of quantified exposures in a variety of industrial settings. Thus the findings for arsenic are notable, particularly in light of the common assumption that a linear extrapolation to low doses is "health protective." From the public health standpoint, the much steeper slopes at low as opposed to high doses in these studies suggest that the use of linear models applied to occupational epidemiologic data may, in some situations, result in an underestimation of the true risks at lower exposures.

\section{Acknowledgments}

This project was supported by the University of California "Health Effects Component of the Toxic Substances Research and Training Program," and by the California Department of Health Services. 
The authors would like to thank Ms C HopenhaynRich, Dr A Wu, and Dr B Langholz for their comments on earlier drafts of the manuscript.

\section{References}

1. International Agency for Research on Cancer (IARC). Some metals and metallic compounds. Lyon: IARC, 1980. (Monographs on the evaluation of the carcinogenic risk of chemicals to humans; vol 23.)

2. California Department of Health Services. Carcinogenicity - human data. In: California Department of Health Services. Health effects of inorganic arsenic compounds: part B of the report to the air resources board on inorganic arsenic. Sacramento, CA: California Department of Health Services, 1990:9-1—9-45.

3. Hertz-Picciotto I, Smith AH, Holtzman D, Lipsett M, Alexeeff G. Synergism between occupational arsenic exposure and smoking in the induction of lung cancer. Epidemiology 1992;3:23-31

4. Enterline PE, Henderson VL, Marsh GM. Exposure to arsenic and respiratory cancer: a reanalysis. Am J Epidemiol 1987;125:929-38.

5. Lee-Feldstein A. Cumulative exposure to arsenic and its relationship to respiratory cancer among copper smelter employees. J Occup Med 1986;28:296-302.

6. Jarup L, Pershagen G, Wall S. Cumulative arsenic exposure and lung cancer in smelter workers: a doseresponse study. Am J Ind Med 1989;15:31-41.

7. Jarup L, Pershagen G. Arsenic exposure, smoking and lung cancer in smelter workers - a case-control study. Am J Epidemiol 1991;134:545-51.

8. Ott MG, Holder BB, Gordon HL. Respiratory cancer and occupational exposure to arsenicals. Arch Environ Health 1974;29:250-5.

9. Taylor PR, Qiao Y-L, Schatzkin A, Yao S-X, Lubin J, Mao B-L, et al. Relation of arsenic exposure to lung cancer among tin miners in Yunnan Province, China. Br J Ind Med 1989;46:881-6.

10. Enterline PE, Marsh GM, Esmen NA, Henderson VL, Callahan CM, Paik M. Some effects of cigarette smoking, arsenic, and $\mathrm{SO}_{2}$ on mortality among US copper smelter workers. J Occup Med 1987;29:831-8.

11. Hertz-Picciotto I, Holtzman D. Dose-response relationship between arsenic inhalation exposure and risk of lung cancer. In: Garrick BJ, Gekler WC, ed. The analysis, communication, and perception of risk. New York, NY: Plenum Press, 1991:137-143

12. Hill AB. The environment and disease: association or causation? President's Address. Proc R Soc Med 1965; 58:295-300.

13. Hertz-Picciotto I. Environmental risk assessment. In: Case B, Talbott E, ed. Introduction to environmental epidemiology. Baltimore, MD: CRC Press, Lewis Publishers. In press.

14. Lee AM, Fraumeni JF. Arsenic and respiratory cancer in man: an occupational study. JNCI 1969;42: 1045-52.

15. Lubin JH, Pottern LM, Blot WJ, Tokudome S, Stone BJ, Fraumeni JF. Respiratory cancer among copper smelter workers: recent mortality statistics. J Occup Med 1981;23:779-84.

16. Enterline PE, Marsh GM. Cancer among workers exposed to arsenic and other substances in a copper smelter. Am J Epidemiol 1982;116:895-911.

17. Lee-Feldstein A. Cumulative arsenic exposure and its relationship to respiratory cancer among copper smelter employees. J Occup Med 1983;28:296-302.

18. Brown CC, Chu KC. Implications of the multistage theory of carcinogenesis applied to occupational arsenic exposure. JNCI 1983;70:455-63.

19. Breslow NE, Day NE. Statistical methods in cancer research; vol II (The design and analysis of cohort studies). Lyon: International Agency for Research on Cancer, 1987.

20. Higgins I, Welch KB, Oh MS, Kryston KL, Burchfiel CM, Wilkinson NM. Arsenic exposure and respiratory cancer in a cohort of 8044 Anaconda smelter workers: a 43-year follow-up study. Report submitted to the Chemical Manufacturers' Association and Smelters Environmental Research Association, 1985.

21. Welch K, Higgins I, Oh M, Burchfiel C. Arsenic exposure, smoking and respiratory cancer in copper smelter workers. Arch Environ Health 1982;37:325 35.

22. Qiao Y-L, Taylor PR, Yao S-X, Schatzkin A, Mao B$\mathrm{L}$, Lubin J, et al. Relation of radon exposure and tobacco use to lung cancer among tin miners in Yunnan Province, China. Am J Ind Med 1989;16:51121.

23. Pershagen G. The epidemiology of human arsenic exposure. In: Fowler BA, ed. Biological and environmental effects of arsenic. New York, NY: Elsevier, 1983: $199-232$.

24. Pershagen G. Lung cancer mortality among men living near an arsenic-emitting smelter. Am J Epidemiol 1985;122:684-94.

25. Rencher AC, Carter MW, McKee DW. A retrospective epidemiological study of mortality at a large western copper smelter. J Occup Med 1977;19:754 8 .

26. Miettinen O. Theoretical epidemiology. New York, NY: John Wiley \& Sons, 1985:117-22.

27. Arrighi HM, Hertz-Picciotto I. An evaluation of methods to control the healthy worker survivor effect: an example using arsenic exposure and respiratory cancer [abstract]. Am J Epidemol 1992;136:952.

28. Robins J. A new approach to causal inference in mortality studies with a sustained exposure period - application to control of the healthy worker survivor effect. Math Modeling 1986;7:1393 - 512.

29. Rappaport SM. Selection of the measures of exposure for epidemiology studies. Appl Occup Environ Hyg 1991;6:448-57.

30. Rappaport S. Assessment of long-term exposures to toxic substances in air. Ann Occup Hyg 1991;35:61121.

31. Armstrong B. The effects of measurement error on estimates of exposure-response relationships. In: Band $P$, ed. Occupational cancer epidemiology. Berlin: Springer Verlag, 1990:50-63.

32. Armstrong B. Effects of measurement errors on relative risk estimates. Am J Epidemiol 1990;132:117684.

33. Foa V, Colombi A, Maroni M, Buratti M, Calzaferri G. The speciation of the chemical forms of arsenic in the biological monitoring of exposure to inorganic arsenic. Sci Total Environ 1984;34:241-59.

34. Buchet JP, Lauwerys R, Roels H. Comparison of urinary excretion of arsenic metabolites after a single oral dose of sodium arsenite, monomethylarsonate, or dimethylarsinate in man. Int Arch Occup Environ Health 1981;48:71-9.

35. Buchet JP, Lauwerys R, Roels H. Urinary excretion of inorganic arsenic and its metabolites after repeated ingestion of sodium metaarsenite by volunteers. Int Arch Occup Environ Health 1981;48:111-8.

36. Vahter M. Environmental and occupational exposure to inorganic arsenic. Acta Pharmacol Toxicol 1986;59: $31-4$.

37. Smith T, Crecelius E, Reading J. Airborne arsenic exposure and excretion of methylated arsenic compounds. Environ Health Perspect 1977;19:89-93.

38. Hopenhayn-Rich C, Smith AH, Goeden H. Human studies do not support the methylation threshold hypothesis for the toxicity of inorganic arsenic. Environ Res. 1993;60:161-77. 
39. Marcus WL, Rispin AS. Threshold carcinogenicity using arsenic as an example. In: Cothern CR, Mehlman MA, Marcus WL, ed. Risk assessment and risk management of industrial and environmental chemicals. Princeton, NJ: Princeton Scientific Publishing Co Inc, 1988:133-58.

40. Li J-H, Rossman TG. Inhibition of DNA ligase activity by arsenite: a possible mechanism of its comutagenesis. Mol Toxicol 1989;2:1-9.

41. Li J-H, Rossman TG. Mechanism of comutagenesis of sodium arsenite with n-methyl-n-nitrosourea. Biol Trace Element Res 1989;21:373-381.

42. Li J-H, Rossman TG. Comutagenesis of sodium arsen- ite with ultraviolet radiation in Chinese hamster V79 cells. Biol Metals 1991;4:197-200.

43. Barrett JC, Lee T-C. Mechanisms of arsenic-induced gene amplification. In: Kellems RE, ed. Gene amplification in mammalian cells: techniques and applications. New York, NY: Marcel Dekker Inc, 1992: $441-6$.

44. Lee T-C, Tanaka N, Lamb PW, Gilman TM, Barrett JC. Induction of gene amplification by arsenic. Science $1988 ; 241: 79-81$.

Received for publication: 28 July 1992 